\title{
ESTRUTURA HORIZONTAL DE UM TRECHO DE FLORESTA OMBRÓFILA DENSA DAS TERRAS BAIXAS NA RESERVA BIOLÓGICA DE SOORETAMA, LINHARES, ES
}

\author{
Alessandro de Paula ${ }^{1}$, João Juares Soares ${ }^{2}$ \\ ${ }^{1}$ Eng.Florestal, Dr., UESB, Vitória da Conquista, BA, Brasil - depaula.alessandro@ gmail.com \\ ${ }^{2}$ Naturalista, Dr., UFSCar, São Carlos, SP, Brasil - juares@ power.ufscar.br \\ Recebido para publicação: 12/04/2010 - Aceito para publicação: 28/11/2010
}

\begin{abstract}
Resumo
Este trabalho teve como objetivo analisar a estrutura fitossociológica horizontal de um trecho da vegetação arbórea de uma floresta de tabuleiro. Foi realizada uma amostragem fitossociológica em 100 parcelas contíguas de 10 × $10 \mathrm{~m}$, sendo amostrados os indivíduos com PAP $\geq 15 \mathrm{~cm}$. Construiuse a distribuição diamétrica e estimou-se o padrão de distribuição espacial das espécies. Foram amostrados 1519 indivíduos, distribuídos entre 265 espécies, 138 gêneros e 44 famílias. O índice de Shannon (H') estimado foi de 4,87 nats/ind. As espécies com os maiores VI foram Rinorea bahiensis (Moric.) Kuntze, Eriotheca macrophylla (K. Schum.) A. Robyns e Sterculia speciosa K. Schum. Em relação aos grupos ecológicos, as secundárias tardias obtiveram mais que o dobro do VC e VI das secundárias iniciais. A distribuição diamétrica apresentada pelas pioneiras foi truncada, sendo que a das secundárias iniciais foi ampla. A predominância de espécies tolerantes ao sombreamento nos estágios iniciais de crescimento reforça a ideia de que o estádio sucessional encontra-se avançado. Foram encontradas 10 espécies com padrão de distribuição espacial agregado e 29 aleatório.

Palavras-chave: Fitossociologia; estrutura horizontal; Floresta Ombrófila Densa; floresta de tabuleiro; floresta atlântica.
\end{abstract}

\begin{abstract}
Horizontal structure of Ombrophilous dense forest of lowlands in Sooretama Biological Reserve, Linhares. This work aimed to analyze horizontal structure of arboreal vegetation from a "tableland" forest. A phytosociological sample was carried out on 100 contiguous plots of $10 \mathrm{X} 10$ meters. We sampled the individuals with $\mathrm{PBH} \geq 15 \mathrm{~cm}$, built up the diametric distribution and estimated spatial species distribution pattern. We sampled 1519 individuals, which were distributed into 265 species, 138 genera and 44 families. Shannon's Index (H') was estimated at 4.87 nats/ind. Species with the highest IV were Rinorea bahiensis (Moric.) Kuntze, Eriotheca macrophylla (K. Schum.) A. Robyns and Sterculia speciosa K. Schum. In relation to ecological groups, the late secondary species obtained CV and IV, twice as much as the early secondary ones. Pioneers presented truncated diametric distribution, as long as the early secondary had a broader one. Shadow tolerant species predominance reinforces that successional stadium is advanced. It had been found 10 species with aggregated spatial distribution and 29 random ones.

Keywords: Phytosociology; horizontal structure; Dense Ombrophilous Forest; tabuleiro forest; atlantic forest.
\end{abstract}

\section{INTRODUÇÃO}

Relatos de naturalistas nos dão a dimensão de quão imponente era a vegetação do norte do Espírito Santo. Os documentos evidenciavam uma floresta esplendorosa, composta por árvores de grande porte, formando um dossel único. O naturalista canadense Charles Frederick Hartt, que visitou a região entre 1865 e 1867, definiu a paisagem com a frase: "Em parte alguma do Brasil, nem mesmo no Pará, vi uma floresta mais exuberante do que a do rio Doce". Em 1885, William John Steains, geógrafo inglês, visitou o rio Doce e fez uma descrição das madeiras e plantas que ali encontrou, com sua classificação e utilização. A visão que nos é dada por esses relatos é efetivamente a de uma terra verdoenga, esverdeada, que, simbolicamente, madura ainda não estava para a penetração do homem branco. Saint-Hillaire, num 
voo de imaginação, diz que ela só termina no Paraguai, após o território das Missões (BORGO et al., 1996).

Trabalhos mais recentes também exaltam a exuberância da floresta de tabuleiros. Peixoto; Gentry (1990) afirmaram que o aspecto mais surpreendente do trabalho realizado na mata de tabuleiro foi a grande riqueza em espécies vegetais. Peixoto; Silva (1997) destacaram que a alta diversidade fez com que a floresta de tabuleiro do norte do Espírito Santo fosse incluída como um dos quatorze centros de alta diversidade vegetal no Brasil. Davis et al. (1997) afirmaram que existe uma alta diversidade de espécies, especialmente em relação à vegetação arbórea. Segundo esses autores, uma característica importante da flora, quando comparada com outras áreas de florestas tropicais úmidas, é a riqueza de lianas, sendo que algumas famílias têm mais espécies de lianas por hectare em Linhares do que em quaisquer outras áreas neotropicais. Rizzini et al. (1997) compararam a floresta de tabuleiro existente na Reserva Natural da Companhia Vale do Rio Doce (RNCVRD) com outros fragmentos florestais da região. Souza et al. (1998a, 1998b) estudaram a composição florística e a estrutura fitossociológica em fragmentos localizados em Pedro Canário (ES) e Caravelas (BA), respectivamente. Jesus; Rolim (2005) estudaram a estrutura horizontal, vertical e interna da floresta de tabuleiro existente na RNCVRD. Paula et al. (2009) discutiram a florística e a estrutura em fragmentos florestais no município de Linhares (ES).

Até meados do século XIX, a penetração para o interior do estado do Espírito Santo foi dificultada pela barreira imposta pelas florestas tropicais, assim como pela reação de grupos nativos e pelas doenças endêmicas, como o impaludismo. A entrada para o "hinterland" foi proibida pela Coroa, a partir da descoberta das minas de ouro, em 1710, quando o governador capitão-geral do estado do Brasil, Lourenço de Almada, por ordem de D. João V, de Portugal, determinou a suspensão da exploração das minas existentes na Capitania do Espírito Santo, com a proibição da construção de estradas para as Minas Gerais, sob "pena de confisco de bens e degredo para Angola” (BORGO et al., 1996).

O Espírito Santo ficou, dessa forma, por três séculos e meio, coberto de florestas que começavam próximas ao mar, atravessando todo o território, galgando as serras do Caparaó e dos Aimorés, e penetrando no estado de Minas Gerais. Em 1810, mais de 85\% do território capixaba se encontrava coberto por mata atlântica (RUSCHI, 1950). Somente na primeira metade do século 20 começou a exploração das riquezas da parte norte, tendo desempenhado o rio Doce, durante muito tempo, o papel de limite natural entre a zona povoada e a região semidesconhecida do norte desse estado (EGLER, 1954).

Com a elevação do nível de vida dos europeus, surgiu uma grande demanda para as madeiras duras das regiões tropicais, assim como culturas que na época eram consideradas supérfluas (café e cacau) passaram a ser essenciais. Esse processo gerou uma grande demanda de materiais de construção à base de madeira, acelerando o corte de árvores na região norte do estado. Isso acarretou um impulso de povoamento mais recente (a partir do final da Segunda Guerra Mundial), com acentuado dinamismo, levando moradores para terras antes registradas nos mapas como desconhecidas (BORGO et al., 1996). Heinsdijk et al. (1965) já alertavam para a expansão das lavouras de café e cacau na região, aliadas à extração de madeiras.

Esse processo levou à fragmentação florestal observada nos dias de hoje. As outrora imponentes florestas de tabuleiro da região norte do Espírito Santo estão atualmente protegidas por poucas unidades de conservação existentes na região (Floresta Nacional do Rio Preto, Floresta Nacional de Goitacazes, Reserva Biológica do Córrego Grande, Reserva Biológica do Córrego do Veado e a Reserva Biológica de Sooretama). E muito pouco, considerando que a Floresta Ombrófila Densa representava 68,5\% da extensão territorial do estado (INSTITUTO DE PESQUISAS DA MATA ATLÂNTICA (IPEMA), 2005).

Com a intenção de avaliar o atual estádio de desenvolvimento do estande florestal, foi proposta a investigação das seguintes hipóteses: o estádio sucessional do estande florestal é avançado; o grupo ecológico predominante na estrutura fitossociológica horizontal é o das espécies tardias; o estande florestal possui um alto índice de diversidade.

Sendo assim, este trabalho teve como objetivo analisar a estrutura fitossociológica horizontal de um trecho da vegetação arbórea remanescente de uma floresta de tabuleiro na Reserva Biológica de Sooretama (ReBio de Sooretama), em Linhares, ES. 


\section{MATERIAL E MÉTODOS}

A ReBio de Sooretama está localizada entre os municípios de Linhares, Sooretama, Vila Valério e Jaguaré, entre os paralelos $18^{\circ} 55^{\prime}$ e $19^{\circ} 05^{\prime}$ de latitude sul e os meridianos $39^{\circ} 55^{\prime}$ e $40^{\circ} 15^{\prime}$ de longitude oeste. Seu perímetro mede $120 \mathrm{~km}$, perfazendo uma área de $24.250 \mathrm{ha}$.

Segundo Anacleto (1997), a diversidade do clima na região deve-se principalmente à grande extensão de baixadas costeiras e diferenças de relevo. Peixoto; Gentry (1990) classificaram o clima da região como tropical úmido $(\mathrm{Am})$, com precipitação pluviométrica média anual de $1.403 \mathrm{~mm}$ e uma estação seca de maio a setembro, podendo chegar a apenas $33 \mathrm{~mm}$ de chuva nos meses de julho e agosto. A média anual de temperatura é de $23,6{ }^{\circ} \mathrm{C}$, com mínima em julho $\left(15,6{ }^{\circ} \mathrm{C}\right)$ e máxima em fevereiro $\left(27,4^{\circ} \mathrm{C}\right)$. Os autores, usando o índice de sazonalidade de Mohr, obtiveram o resultado $(\mathrm{Q}=33,3)$, que coloca a área estudada no limite entre o úmido e o levemente sazonal.

Segundo Instituto Brasileiro de Geografia e Estatística (IBGE) (2004), a vegetação da região norte do estado do Espírito Santo ocorre sob um clima ombrófilo sem período biologicamente seco durante o ano e, excepcionalmente, com até dois meses de umidade escassa, devendo ser classificada como Floresta Ombrófila Densa. Especificamente em relação ao estande estudado, a vegetação pode ser enquadrada como Floresta Ombrófila Densa das Terras Baixas. Essa vegetação é comumente chamada de floresta dos tabuleiros. Rizzini (1997) definiu-a como o corpo florestal que ocorre desde Pernambuco até o estado do Rio de Janeiro. $\mathrm{O}$ autor caracteriza sua área central como imponente e define sua distribuição como sendo da região sul da Bahia até o norte do Espírito Santo. Segundo o mesmo autor, trata-se de uma faixa litorânea, por dentro das alvas areias quaternárias (ditas areões, na Bahia austral), que suportam a restinga. $\mathrm{O}$ nome tabuleiro refere-se à topografia, já que se trata de uma faixa quase plana ou suavemente ondulada, elevando-se de 20 a $200 \mathrm{~m}$ acima do nível do mar.

Aguirre (1992) descreve a topografia como mais ou menos acidentada, ora formando elevações de altura máxima de $50 \mathrm{~m}$, ora apresentando chapadas interrompidas apenas pelos talvegues dos córregos que se escoam para o rio Barra Seca ou para o córrego Cupido. Especificamente em relação às parcelas, elas foram locadas em uma área plana, não havendo variação topográfica entre as unidades amostrais.

O solo é formado a partir de sedimentos terciários (pliocênicos) da Formação Barreiras. Segundo IBGE (1977), sua origem continental poderia ser buscada na intensa erosão das rochas dos maciços cristalinos, sob condições provavelmente secas. Após sua deposição, esses pacotes de rocha teriam sido afetados pela tectônica e pelas oscilações do nível do mar, ocorridas durante o Quaternário. Segundo Ferreira et al. (1981), os solos são constituídos pelos Latossolos Vermelho Amarelos Distróficos, excetuando uma estreita faixa à margem da lagoa do Macuco e do rio Barra Seca, constituída pela associação Gley Húmico e solos orgânicos.

O método empregado na amostragem fitossociológica foi o de parcelas (MUELLER-DOMBOIS; ELLENBERG, 1974), sendo a amostragem realizada em um hectare quadrado, com parcelas contíguas de $10 \times 10 \mathrm{~m}$, resultando em 100 parcelas. A primeira estaca da parcela 1 encontra-se nas coordenadas UTM 410589 E e 7838826 N. No levantamento, foram amostrados todos os indivíduos do estrato arbóreo que apresentassem perímetro do tronco à altura do peito (PAP) maior ou igual a $15 \mathrm{~cm}$.

As espécies foram classificadas em três grupos ecológicos, seguindo a classificação de Gandolfi et al. (1995), com base na categorização realizada por Jesus; Rolim (2005).

Os parâmetros fitossociológicos estimados foram: densidade relativa (DR), área basal (AB), dominância relativa (DoR), frequência absoluta (FA) e frequência relativa (FR), utilizados na composição dos valores de cobertura (VC) e importância (VI), que foram interpretados segundo Mueller-Dombois; Ellenberg (1974), Pielou (1975) e Förster (1973, citado por ROSOT et al., 1982), utilizando o programa Fitopac 1 (SHEPHERD, 1995).

De acordo com o proposto por Martins (1993), foram consideradas raras as espécies que apresentaram um indivíduo por hectare.

A distribuição diamétrica foi feita por meio do programa Diamfito, desenvolvido por Luiz Pacheco Motta no Departamento de Biologia Vegetal da Universidade Federal de Viçosa (MG). Para a distribuição diamétrica, utilizou-se como primeiro centro de classe $7,5 \mathrm{~cm}$ de diâmetro e amplitude de $10 \mathrm{~cm}$.

Para a obtenção das estimativas do padrão de distribuição das espécies com mais de um indivíduo, foi utilizado o índice estandardizado de Morisita $\left(\mathrm{I}_{\mathrm{p}}\right)$. As expressões matemáticas (KREBS, 1989) utilizadas para os cálculos foram: 
- $\quad \mathrm{I}_{\mathrm{d}}=\mathrm{n}\left[\sum \mathrm{x}_{\mathrm{i}}^{2}-\sum \mathrm{x}_{\mathrm{i}} /\left(\sum \mathrm{x}_{\mathrm{i}}\right)^{2}-\sum \mathrm{x}_{\mathrm{i}}\right]$

- $\mathrm{M}_{\mathrm{u}}=\chi_{0,975}^{2}-\mathrm{n}+\sum \mathrm{x}_{\mathrm{i}} /\left(\sum \mathrm{x}_{\mathrm{i}}\right)-1$

- $\mathrm{M}_{\mathrm{a}}=\chi_{0,025}^{2}-\mathrm{n}+\sum \mathrm{x}_{\mathrm{i}} /\left(\sum \mathrm{x}_{\mathrm{i}}\right)-1$

$$
\begin{aligned}
\text { Se } I_{d} \geq M_{a} & >1,0, \text { usa-se: } \\
-\quad I_{p} & =0,5+0,5\left(I_{d}-M_{a} / n-M_{a}\right) \\
\text { Se } M_{a} & >I_{d} \geq 1,0, \text { usa-se: } \\
-\quad I_{p} & =0,5\left(I_{d}-1 / M_{u}-1\right) \\
\text { Se } 1,0 & >I_{d}>M_{u} \text {, usa-se: } \\
-\quad I_{p} & =-0,5\left(I_{d}-1 / M_{u}-1\right) \\
\text { Se } 1,0 & >M_{u}>I_{d} \text {, usa-se: } \\
-\quad I_{p} & =-0,5+0,5\left(I_{d}-M_{u} / M_{u}\right)
\end{aligned}
$$

Em que: $I_{d}=$ índice de dispersão de Morisita;

$\mathrm{n}=$ número de parcelas;

$\sum \mathrm{x}_{\mathrm{i}}=$ somatória do número de indivíduos da espécie $\mathrm{i}$;

$\sum \mathrm{x}_{\mathrm{i}}{ }^{2}=$ somatória do quadrado do número de indivíduos da espécie i em cada parcela;

$\mathrm{M}_{\mathrm{u}}=$ índice de uniformidade;

$\mathrm{M}_{\mathrm{a}}=$ índice de agregação.

A interpretação do $I_{p}$ teve o seguinte critério: $I_{p} \geq 0,5$, padrão espacial agregado; $I_{p} \leq-0,5$, padrão uniforme; e -0,5 $>\mathrm{I}_{\mathrm{p}}<0,5$, padrão aleatório (KREBS, 1989).

Para apresentação da listagem florística, foi adotado o sistema APG II (2003). Os indivíduos que apresentaram estruturas férteis foram depositados no Herbário do Museu de Biologia Mello Leitão (Santa Teresa, ES).

\section{RESULTADOS E DISCUSSÃO}

Foram amostrados 1519 indivíduos, distribuídos entre 265 espécies, 138 gêneros, 44 famílias e três morfoespécies (sendo estas denominadas como "Indet"). O índice de Shannon (H') encontrado foi de 4,87 nats/ind., sendo esse valor um dos mais expressivos em relação às Florestas Ombrófilas Densas da região Sudeste. Como elementos de comparação, podemos citar os trabalhos de Thomaz; Monteiro (1997), que encontraram um índice de 5,51 nats/ind. na Reserva Biológica Santa Lúcia (ES); López (1996), com 5,11 nats/ind. na Fazenda Caliman (ES); Jesus; Rolim (2005), com 5,04 nats/ind. na Reserva Natural da Companhia Vale do Rio Doce (ES); Salomão (1998), com 4,71 nats/ind. na Floresta Nacional do Rio Preto (ES); Souza et al. (1998a), com 4,64 nats em Pedro Canário (ES); Silva (1989), com 4,36 nats na Reserva Florestal Augusto Ruschi (SP); Silva; Leitão Filho (1982), com 4,07 nats/ind. na Estação Ecológica do I.A.C. (SP); Paula et al. (2009), com 3,71 nats/ind. na Lagoa Juparanã (ES); e Silva; Nascimento (2001), que encontraram um índice de 3,21 nats/ind. na Mata do Carvão (RJ).

A espécie que apresentou o maior número de indivíduos e por consequência a maior DR foi Rinorea bahiensis (Moric.) Kuntze, muito à frente de Sterculia speciosa K. Schum., Eugenia ubensis Cambess. e Ecclinusa ramiflora Mart. (Tabela 1). No trabalho realizado por Jesus; Rolim (2005) em área próxima ao presente levantamento, as espécies $R$. bahiensis, E. ubensis e E. ramiflora também figuram entre as de maior $\mathrm{DR}$, com valores semelhantes aos encontrados neste trabalho. Apesar do maior número de indivíduos amostrados, $R$. bahiensis obteve a segunda posição em relação a $\mathrm{AB}$, devido ao pequeno porte apresentado pela maioria de seus indivíduos (Tabela 1). Já Eriotheca macrophylla (K. Schum.) A. Robyns, com um pouco mais de um décimo do número de indivíduos de $R$. bahiensis, atingiu um valor de $\mathrm{AB}$ maior. Esse destaque é reflexo do grande porte de um único indivíduo $(780 \mathrm{~cm})$, sendo este o de maior perímetro da amostragem. Dentre os indivíduos amostrados de R. bahiensis, 41 deles (37\%) apresentaram PAP acima de $50 \mathrm{~cm}$. Outras espécies apresentaram indivíduos de grande porte, como Ficus gomelleira Kunth \& C.D. Bouché, com dois indivíduos amostrados, sendo um deles com 140,2 cm e outro com $680 \mathrm{~cm}$, e ainda Coussapoa curranii S.F. Blake, com apenas um indivíduo, medindo perímetro do tronco de $548 \mathrm{~cm}$. 
Tabela 1. Lista das espécies amostradas no levantamento fitossociológico realizado em um estande florestal na Reserva Biológica de Sooretama, ordenadas decrescentemente por VI, sendo: GE - grupo ecológico, PI - pioneira, SI - secundária inicial, ST - secundária tardia, IN - indeterminada, NI número de indivíduos/ha, DR - densidade relativa $(\%), \mathrm{AB}$ - área basal $\left(\mathrm{m}^{2} / \mathrm{ha}\right)$, DoR dominância relativa (\%), FA - frequência absoluta (\%), FR - frequência relativa (\%), VC - valor de cobertura, VI - valor de importância, $I_{d}$ - índice de dispersão de Morisita, $I_{p}$ - índice estandarlizado de Morisita, Aleat - padrão aleatório e Agreg - padrão agregado.

Table 1. List of species in the phytosociological survey carried out in a forest stand in Sooretama Biological Reserve, sorted decreasingly by VI, as follows: GE - ecological group, PI - pioneer, SI - secondary initial, ST - late secondary, IN - undetermined, NI - number of individuals/ha, DR - relative density $(\%), \mathrm{AB}$ - basal area $\left(\mathrm{m}^{2} / \mathrm{ha}\right)$, DoR - relative dominance $(\%), \mathrm{FA}$ - absolute frequency $(\%)$, FR relative frequency (\%), VC - value covering, VI - importance value, $\mathrm{I}_{d}$ - index of dispersion of Morisita, $I_{p}$ - estandarlizado Morisita index, Aleat - random pattern and Agreg - aggregate pattern.

\begin{tabular}{|c|c|c|c|c|c|c|c|c|c|c|c|c|}
\hline Espécie & GE & NI & DR & $\mathbf{A B}$ & DoR & FA & FR & vC & VI & Id & Ip & Padrão \\
\hline Rinorea bahiensis (Moric.) Kuntze & ST & 111 & 7,31 & 46,86 & 9,94 & 72 & 5,36 & 17,25 & 22,61 & 0,85 & $-0,33$ & Aleat \\
\hline Eriotheca macrophylla (K. Schum.) A. Robyns & SI & 14 & 0,92 & 48,89 & 10,37 & 14 & 1,04 & 11,29 & 12,33 & 0,00 & $-0,26$ & Aleat \\
\hline Sterculia speciosa K. Schum. & ST & 63 & 4,15 & 18,01 & 3,82 & 41 & 3,05 & 7,97 & 11,02 & 1,89 & 0,50 & Agreg \\
\hline Ficus gomelleira Kunth \& C.D. Bouché & SI & 2 & 0,13 & 38,58 & 8,18 & 2 & 0,15 & 8,31 & 8,46 & - & - & - \\
\hline Dialium guianense (Aubl.) Sandwith & ST & 31 & 2,04 & 15,73 & 3,34 & 27 & 2,01 & 5,38 & 7,39 & 0,86 & $-0,08$ & Aleat \\
\hline Hydrogaster trinervis Kuhlm. & SI & 13 & 0,86 & 22,79 & 4,83 & 13 & 0,97 & 5,69 & 6,66 & 0,00 & $-0,24$ & Aleat \\
\hline Eugenia ubensis Cambess. & $\mathrm{ST}$ & 41 & 2,70 & 0,59 & 1,26 & 35 & 2,61 & 3,96 & 6,56 & 0,85 & $-0,12$ & Aleat \\
\hline Ecclinusa ramiflora Mart. & $\mathrm{ST}$ & 40 & 2,63 & 0,36 & 0,77 & 33 & 2,46 & 3,40 & 5,86 & 1,03 & $-0,02$ & Aleat \\
\hline Coussapoa curranii S.F. Blake & SI & 1 & 0,07 & 23,90 & 5,07 & 1 & 0,07 & 5,13 & 5,21 & - & - & - \\
\hline Schoepfia oblongifolia Turez & ST & 30 & 1,97 & 0,33 & 0,70 & 25 & 1,86 & 2,68 & 4,54 & 1,15 & $-0,09$ & Aleat \\
\hline Pouteria hispida Eyma & ST & 20 & 1,32 & 0,87 & 1,84 & 18 & 1,34 & 3,15 & 4,49 & 1,05 & $-0,02$ & Aleat \\
\hline Pterocarpus rohrii Vahl & SI & 8 & 0,53 & 15,71 & 3,33 & 8 & 0,60 & 3,86 & 4,46 & - & - & - \\
\hline Eugenia excelsa $\mathrm{O}$. Berg & $\mathrm{ST}$ & 30 & 1,97 & 0,23 & 0,49 & 23 & 1,71 & 2,47 & 4,18 & 2,30 & 0,50 & Agreg \\
\hline Terminalia kuhlmannii Alwan \& Stace & SI & 5 & 0,33 & 15,70 & 3,33 & 5 & 0,37 & 3,66 & 4,03 & - & - & - \\
\hline $\begin{array}{l}\text { Calyptranthes lucida var. polyantha (O. Berg) D. } \\
\text { Legrand }\end{array}$ & ST & 30 & 1,97 & 0,16 & 0,34 & 23 & 1,71 & 2,31 & 4,02 & 1,84 & 0,50 & Agreg \\
\hline Eugenia microcarpa $\mathrm{O}$. Berg & ST & 30 & 1,97 & 0,18 & 0,38 & 20 & 1,49 & 2,36 & 3,85 & 3,45 & 0,51 & Agreg \\
\hline Carpotroche brasiliensis (Raddi) Endl. & ST & 25 & 1,65 & 0,18 & 0,39 & 22 & 1,64 & 2,03 & 3,67 & 1,00 & 0,00 & Aleat \\
\hline Quararibea penduliflora (St.Hil.) K. Schum. & $\mathrm{ST}$ & 24 & 1,58 & 0,28 & 0,60 & 19 & 1,41 & 2,18 & 3,60 & 2,54 & 0,50 & Agreg \\
\hline Neoraputia alba (Nees \& Mart.) Emmerich & ST & 25 & 1,65 & 0,23 & 0,49 & 19 & 1,41 & 2,13 & 3,55 & 2,67 & 0,50 & Agreg \\
\hline Melanoxylon brauna Schott & ST & 9 & 0,59 & 0,96 & 2,03 & 9 & 0,67 & 2,62 & 3,29 & - & - & - \\
\hline Caryodendron grandifolium (Müll. Arg.) Pax & $\mathrm{ST}$ & 23 & 1,51 & 0,17 & 0,36 & 18 & 1,34 & 1,87 & 3,21 & 2,37 & 0,50 & Agreg \\
\hline Stephanopodium blanchetianum Baill. & $\mathrm{ST}$ & 20 & 1,32 & 0,14 & 0,29 & 19 & 1,41 & 1,61 & 3,02 & 0,53 & $-0,18$ & Aleat \\
\hline Senefeldera multiflora Mart. & $\mathrm{ST}$ & 19 & 1,25 & 0,22 & 0,46 & 17 & 1,27 & 1,71 & 2,98 & 1,75 & $-0,27$ & Aleat \\
\hline Sorocea guilleminiana Gaudich. & ST & 19 & 1,25 & 0,18 & 0,38 & 18 & 1,34 & 1,63 & 2,97 & 0,58 & $-0,15$ & Aleat \\
\hline Eugenia tinguyensis Cambess. & ST & 21 & 1,38 & 0,08 & 0,17 & 18 & 1,34 & 1,55 & 2,89 & 1,43 & $-0,17$ & Aleat \\
\hline Lecythis lanceolata Poir. & $\mathrm{ST}$ & 7 & 0,46 & 0,84 & 1,78 & 7 & 0,52 & 2,24 & 2,76 & - & - & - \\
\hline Virola gardneri (A. DC.) Warb. & $\mathrm{ST}$ & 12 & 0,79 & 0,53 & 1,12 & 10 & 0,74 & 1,91 & 2,66 & 3,03 & $-0,45$ & Aleat \\
\hline Sclerolobium striatum Dwyer & $\mathrm{ST}$ & 12 & 0,79 & 0,40 & 0,86 & 12 & 0,89 & 1,65 & 2,54 & 0,00 & $-0,22$ & Aleat \\
\hline Eugenia stictosepala Kiaersk. & $\mathrm{ST}$ & 18 & 1,18 & 0,05 & 0,11 & 16 & 1,19 & 1,29 & 2,48 & 1,31 & $-0,11$ & Aleat \\
\hline Couratari asterotricha Prance & SI & 6 & 0,39 & 0,66 & 1,39 & 6 & 0,45 & 1,79 & 2,24 & - & - & - \\
\hline Eschweilera ovata (Cambess.) Miers & ST & 11 & 0,72 & 0,26 & 0,55 & 11 & 0,82 & 1,28 & 2,09 & 0,00 & $-0,20$ & Aleat \\
\hline Eugenia platysema $\mathrm{O}$. Berg & $\mathrm{ST}$ & 11 & 0,72 & 0,26 & 0,55 & 11 & 0,82 & 1,27 & 2,09 & 0,00 & $-0,20$ & Aleat \\
\hline Ravenia infelix Vell. & ST & 17 & 1,12 & 0,04 & 0,09 & 11 & 0,82 & 1,21 & 2,03 & 5,88 & 0,52 & Agreg \\
\hline Siparuna reginae (Tul.) A. DC. & ST & 14 & 0,92 & 0,09 & 0,20 & 12 & 0,89 & 1,12 & 2,01 & 2,20 & $-0,31$ & Aleat \\
\hline Licania salzmannii (Hook. f.) Fritsch & ST & 2 & 0,13 & 0,81 & 1,72 & 2 & 0,15 & 1,86 & 2,00 & - & - & - \\
\hline Protium warmingianum March. & ST & 10 & 0,66 & 0,35 & 0,74 & 8 & 0,60 & 1,40 & 1,99 & 4,44 & 0,51 & Agreg \\
\hline Micropholis cuneata (Raunk.) Pierre ex Glaz. & ST & 12 & 0,79 & 0,17 & 0,36 & 11 & 0,82 & 1,15 & 1,97 & 1,52 & $-0,11$ & Aleat \\
\hline Guapira subferruginosa (Mart. ex Schum.) Lundell & SI & 13 & 0,86 & 0,09 & 0,18 & 12 & 0,89 & 1,04 & 1,93 & 1,28 & $-0,07$ & Aleat \\
\hline $\begin{array}{l}\text { Vatairea heteroptera (Allemão) Ducke ex de Assis } \\
\text { Iglesias }\end{array}$ & SI & 1 & 0,07 & 0,81 & 1,72 & 1 & 0,07 & 1,78 & 1,86 & - & - & - \\
\hline
\end{tabular}

FLORESTA, Curitiba, PR, v. 41, n. 2, p. 321-334, abr./jun. 2011.

Paula, A. de; Soares, J. J. 


\begin{tabular}{|c|c|c|c|c|c|c|c|c|c|c|c|c|}
\hline Marlierea succrei G.M. Barroso \& Peixoto & SI & 12 & 0,79 & 0,08 & 0,18 & 12 & 0,89 & 0,97 & 1,86 & 0,00 & $-0,22$ & Aleat \\
\hline Geissospermum laeve (Vell.) Miers & ST & 12 & 0,79 & 0,08 & 0,16 & 12 & 0,89 & 0,95 & 1,84 & 0,00 & $-0,22$ & Aleat \\
\hline Clarisia racemosa Ruiz \& Pav. & ST & 12 & 0,79 & 0,14 & 0,30 & 10 & 0,74 & 1,09 & 1,83 & 3,03 & $-0,45$ & Aleat \\
\hline Campomanesia guazumifolia (Cambess.) O. Berg & SI & 12 & 0,79 & 0,06 & 0,12 & 12 & 0,89 & 0,91 & 1,80 & 0,00 & $-0,22$ & Aleat \\
\hline Ocotea elegans $\mathrm{Mez}$ & ST & 12 & 0,79 & 0,05 & 0,11 & 12 & 0,89 & 0,90 & 1,79 & 0,00 & $-0,22$ & Aleat \\
\hline Mollinedia marquetiana Peixoto & ST & 11 & 0,72 & 0,04 & 0,08 & 11 & 0,82 & 0,81 & 1,63 & 0,00 & $-0,20$ & Aleat \\
\hline Eugenia pinhaesensis Mattos & ST & 11 & 0,72 & 0,07 & 0,14 & 10 & 0,74 & 0,86 & 1,61 & 1,82 & $-0,17$ & Aleat \\
\hline Guapira noxia (Netto) Lundell & SI & 9 & 0,59 & 0,15 & 0,32 & 9 & 0,67 & 0,91 & 1,58 & - & - & - \\
\hline Clarisia ilicifolia (Spreng.) Lanj. \& Rossberg & ST & 11 & 0,72 & 0,05 & 0,10 & 10 & 0,74 & 0,82 & 1,56 & 1,82 & $-0,17$ & Aleat \\
\hline Ocotea confertiflora (Meisn.) Mez & ST & 9 & 0,59 & 0,16 & 0,33 & 8 & 0,60 & 0,92 & 1,52 & - & - & - \\
\hline Drypetes sp. & IN & 7 & 0,46 & 0,25 & 0,53 & 7 & 0,52 & 0,99 & 1,51 & - & - & - \\
\hline Lecythis lurida (Miers) S.A. Mori & ST & 5 & 0,33 & 0,37 & 0,79 & 5 & 0,37 & 1,12 & 1,49 & - & - & - \\
\hline $\begin{array}{l}\text { Beilschmiedia linharensis Sa. Nishida \& van der } \\
\text { Werff }\end{array}$ & ST & 9 & 0,59 & 0,09 & 0,20 & 9 & 0,67 & 0,79 & 1,46 & - & - & - \\
\hline Marlierea obversa D. Legrand & ST & 9 & 0,59 & 0,09 & 0,20 & 9 & 0,67 & 0,79 & 1,46 & - & - & - \\
\hline Sloanea granulosa Ducke & ST & 7 & 0,46 & 0,21 & 0,45 & 7 & 0,52 & 0,91 & 1,43 & - & - & - \\
\hline Casearia commersoniana Cambess. & ST & 9 & 0,59 & 0,05 & 0,11 & 9 & 0,67 & 0,70 & 1,37 & - & - & - \\
\hline Bombacopsis stenopetala (Casar.) A. Robyns & SI & 4 & 0,26 & 0,36 & 0,77 & 4 & 0,30 & 1,03 & 1,33 & - & - & - \\
\hline Protium heptaphyllum (Aubl.) Marchand & SI & 7 & 0,46 & 0,15 & 0,32 & 7 & 0,52 & 0,78 & 1,30 & - & - & - \\
\hline Thyrsodium schomburgkianum Benth. & SI & 10 & 0,66 & 0,06 & 0,12 & 7 & 0,52 & 0,77 & 1,30 & 8,89 & 0,53 & Agreg \\
\hline Machaerium ovalifolium Glaz. ex Rudd & ST & 8 & 0,53 & 0,07 & 0,15 & 8 & 0,60 & 0,68 & 1,28 & - & - & - \\
\hline Eugenia cuspidata Phil. & ST & 9 & 0,59 & 0,03 & 0,07 & 8 & 0,60 & 0,66 & 1,26 & - & - & - \\
\hline Neomitranthes langsdorfii (O. Berg) Mattos & ST & 8 & 0,53 & 0,05 & 0,11 & 8 & 0,60 & 0,63 & 1,23 & - & - & - \\
\hline Guapira opposita (Vell.) Reitz & SI & 9 & 0,59 & 0,05 & 0,10 & 7 & 0,52 & 0,70 & 1,22 & - & - & - \\
\hline Pouteria bangii (Rusby) T.D. Penn. & ST & 7 & 0,46 & 0,11 & 0,22 & 7 & 0,52 & 0,69 & 1,21 & - & - & - \\
\hline Oxandra sp. & SI & 8 & 0,53 & 0,05 & 0,11 & 7 & 0,52 & 0,64 & 1,16 & - & - & - \\
\hline Aspidosperma illustre (Vell.) Kuhlm. \& Pirajá & ST & 3 & 0,20 & 0,34 & 0,72 & 3 & 0,22 & 0,91 & 1,14 & - & - & - \\
\hline Myrcia lineata (O. Berg) Nied. & ST & 6 & 0,39 & 0,14 & 0,29 & 6 & 0,45 & 0,68 & 1,13 & - & - & - \\
\hline Inga hispida Schott ex Benth. & ST & 8 & 0,53 & 0,04 & 0,08 & 7 & 0,52 & 0,61 & 1,13 & - & - & - \\
\hline Guarea penningtoniana Pinheiro & ST & 8 & 0,53 & 0,07 & 0,14 & 6 & 0,45 & 0,67 & 1,12 & - & - & - \\
\hline Eugenia sp.4 & ST & 7 & 0,46 & 0,06 & 0,13 & 7 & 0,52 & 0,59 & 1,12 & - & - & - \\
\hline Crepidospermum atlanticum Daly & SI & 6 & 0,39 & 0,11 & 0,24 & 6 & 0,45 & 0,64 & 1,08 & - & - & - \\
\hline Eugenia ligustrina (Sw.) Willd. & ST & 7 & 0,46 & 0,03 & 0,07 & 7 & 0,52 & 0,53 & 1,05 & - & - & - \\
\hline Pouteria sp. & ST & 7 & 0,46 & 0,03 & 0,07 & 7 & 0,52 & 0,53 & 1,05 & - & - & - \\
\hline Pouteria coelomatica Rizzini & ST & 3 & 0,20 & 0,29 & 0,62 & 3 & 0,22 & 0,82 & 1,04 & - & - & - \\
\hline Inga capitata Desv. & ST & 6 & 0,39 & 0,09 & 0,19 & 6 & 0,45 & 0,58 & 1,03 & - & - & - \\
\hline Citronella paniculata (Mart.) R.A. Howard & SI & 7 & 0,46 & 0,02 & 0,05 & 7 & 0,52 & 0,51 & 1,03 & - & - & - \\
\hline Copaifera lucens Dwyer & SI & 2 & 0,13 & 0,32 & 0,67 & 2 & 0,15 & 0,80 & 0,95 & - & - & - \\
\hline Tabebuia obtusifolia (Cham.) Bureau & SI & 4 & 0,26 & 0,18 & 0,38 & 4 & 0,30 & 0,65 & 0,95 & - & - & - \\
\hline Lonchocarpus cultratus (Vell.) Tozzi \& H.C. Lima & SI & 5 & 0,33 & 0,12 & 0,24 & 5 & 0,37 & 0,57 & 0,95 & - & - & - \\
\hline $\begin{array}{l}\text { Trichilia lepidota subsp. schumanniana (Harms) } \\
\text { T.D. Penn. }\end{array}$ & ST & 6 & 0,39 & 0,05 & 0,11 & 6 & 0,45 & 0,50 & 0,95 & - & - & - \\
\hline Tabebuia riodocensis A.H. Gentry & SI & 2 & 0,13 & 0,30 & 0,65 & 2 & 0,15 & 0,78 & 0,93 & - & - & - \\
\hline Marlierea strigipes $\mathrm{O}$. Berg & ST & 6 & 0,39 & 0,08 & 0,17 & 5 & 0,37 & 0,56 & 0,93 & - & - & - \\
\hline Aspidosperma cylindrocarpon Mull. Arg. & ST & 6 & 0,39 & 0,08 & 0,16 & 5 & 0,37 & 0,55 & 0,93 & - & - & - \\
\hline Rheedia gardneriana Planch. \& Triana & ST & 6 & 0,39 & 0,04 & 0,09 & 6 & 0,45 & 0,48 & 0,93 & - & - & - \\
\hline Jacaranda puberula Cham. & SI & 6 & 0,39 & 0,03 & 0,07 & 6 & 0,45 & 0,46 & 0,91 & - & - & - \\
\hline Trichilia pallens C. DC. & ST & 6 & 0,39 & 0,03 & 0,06 & 6 & 0,45 & 0,45 & 0,90 & - & - & - \\
\hline Ocotea sp. & ST & 6 & 0,39 & 0,03 & 0,05 & 6 & 0,45 & 0,45 & 0,89 & - & - & - \\
\hline Randia armata (Sw.) DC. & SI & 6 & 0,39 & 0,02 & 0,05 & 6 & 0,45 & 0,44 & 0,89 & - & - & - \\
\hline Duguetia flagellaris Huber & ST & 6 & 0,39 & 0,02 & 0,04 & 6 & 0,45 & 0,44 & 0,88 & - & - & - \\
\hline Joannesia princeps Vell. & PI & 6 & 0,39 & 0,05 & 0,09 & 5 & 0,37 & 0,49 & 0,86 & - & - & - \\
\hline Swartzia simplex var. ochnacea (DC.) R.S. Cowan & ST & 3 & 0,20 & 0,20 & 0,43 & 3 & 0,22 & 0,62 & 0,85 & - & - & - \\
\hline Aspidosperma discolor A. DC. & ST & 5 & 0,33 & 0,11 & 0,22 & 4 & 0,30 & 0,55 & 0,85 & - & - & - \\
\hline Myrciaria amazonica $\mathrm{O}$. Berg & ST & 4 & 0,26 & 0,12 & 0,26 & 4 & 0,30 & 0,52 & 0,82 & - & - & - \\
\hline Chrysophyllum lucentifolium Cronquist & ST & 4 & 0,26 & 0,14 & 0,30 & 3 & 0,22 & 0,56 & 0,78 & - & - & - \\
\hline
\end{tabular}




\begin{tabular}{|c|c|c|c|c|c|c|c|c|c|c|c|c|}
\hline Inga flagelliformis (Vell.) Mart. & ST & 5 & 0,33 & 0,04 & 0,07 & 5 & 0,37 & 0,40 & 0,78 & - & - & - \\
\hline Tachigali paratyensis (Vell.) Lima & SI & 2 & 0,13 & 0,23 & 0,48 & 2 & 0,15 & 0,61 & 0,76 & - & - & - \\
\hline Plinia rivularis (Cambess.) A.D. Rotman & ST & 4 & 0,26 & 0,09 & 0,18 & 4 & 0,30 & 0,45 & 0,74 & - & - & - \\
\hline Simarouba amara Aubl. & SI & 3 & 0,20 & 0,15 & 0,31 & 3 & 0,22 & 0,51 & 0,73 & - & - & - \\
\hline Cupania rugosa Radlk. & ST & 4 & 0,26 & 0,08 & 0,17 & 4 & 0,30 & 0,43 & 0,73 & - & - & - \\
\hline Hirtella hebeclada Moric. ex DC. & ST & 4 & 0,26 & 0,08 & 0,17 & 4 & 0,30 & 0,43 & 0,73 & - & - & - \\
\hline Licania kunthiana Hook. f. & ST & 4 & 0,26 & 0,08 & 0,17 & 4 & 0,30 & 0,43 & 0,73 & - & - & - \\
\hline Cupania scrobiculata Rich. & ST & 5 & 0,33 & 0,02 & 0,03 & 5 & 0,37 & 0,36 & 0,73 & - & - & - \\
\hline Glycydendron amazonicum Ducke & SI & 2 & 0,13 & 0,20 & 0,43 & 2 & 0,15 & 0,56 & 0,71 & - & - & - \\
\hline Brosimum guianense (Aubl.) Huber & ST & 3 & 0,20 & 0,13 & 0,28 & 3 & 0,22 & 0,48 & 0,70 & - & - & - \\
\hline Chrysophyllum jamaicense Eichler & ST & 5 & 0,33 & 0,02 & 0,04 & 4 & 0,30 & 0,37 & 0,67 & - & - & - \\
\hline Ormosia nitida Vogel & SI & 4 & 0,26 & 0,05 & 0,10 & 4 & 0,30 & 0,37 & 0,67 & - & - & - \\
\hline Brosimum lactescens (S. Moore) C.C. Berg & SI & 2 & 0,13 & 0,18 & 0,38 & 2 & 0,15 & 0,51 & 0,66 & - & - & - \\
\hline Myrciaria delicatula (DC.) O. Berg & ST & 1 & 0,07 & 0,23 & 0,49 & 1 & 0,07 & 0,56 & 0,63 & - & - & - \\
\hline Inga cylindrica (Vell.) Mart. & SI & 4 & 0,26 & 0,03 & 0,06 & 4 & 0,30 & 0,33 & 0,63 & - & - & - \\
\hline Xylopia laevigata (Mart.) R. E. Fries & ST & 4 & 0,26 & 0,03 & 0,06 & 4 & 0,30 & 0,33 & 0,62 & - & - & - \\
\hline Zollernia latifolia Benth. & ST & 4 & 0,26 & 0,03 & 0,06 & 4 & 0,30 & 0,32 & 0,62 & - & - & - \\
\hline Cathedra sp. & IN & 1 & 0,07 & 0,22 & 0,47 & 1 & 0,07 & 0,53 & 0,61 & - & - & - \\
\hline Brosimum glaziovii Taub. & SI & 4 & 0,26 & 0,02 & 0,05 & 4 & 0,30 & 0,31 & 0,61 & - & - & - \\
\hline Parinari parvifolia Sandwith & ST & 4 & 0,26 & 0,02 & 0,05 & 4 & 0,30 & 0,31 & 0,61 & - & - & - \\
\hline Campomanesia espiritosantensis Landrum & ST & 4 & 0,26 & 0,02 & 0,04 & 4 & 0,30 & 0,30 & 0,60 & - & - & - \\
\hline Duguetia bahiensis Maas & ST & 4 & 0,26 & 0,02 & 0,03 & 4 & 0,30 & 0,30 & 0,60 & - & - & - \\
\hline Licania heteromorpha Benth. & ST & 4 & 0,26 & 0,02 & 0,03 & 4 & 0,30 & 0,30 & 0,60 & - & - & - \\
\hline Pouteria bapeba T.D. Penn. & ST & 4 & 0,26 & 0,02 & 0,04 & 4 & 0,30 & 0,30 & 0,60 & - & - & - \\
\hline Capparis brasiliana DC. & SI & 4 & 0,26 & 0,01 & 0,03 & 4 & 0,30 & 0,29 & 0,59 & - & - & - \\
\hline Pourouma mollis subsp. mollis Trécul & SI & 4 & 0,26 & 0,04 & 0,09 & 3 & 0,22 & 0,36 & 0,58 & - & - & - \\
\hline Chrysophyllum splendens Spreng. & ST & 3 & 0,20 & 0,07 & 0,15 & 3 & 0,22 & 0,35 & 0,57 & - & - & - \\
\hline Ocotea divaricata (Nees) $\mathrm{Mez}$ & ST & 4 & 0,26 & 0,04 & 0,09 & 3 & 0,22 & 0,35 & 0,57 & - & - & - \\
\hline Pouteria filipes Eyma & ST & 2 & 0,13 & 0,13 & 0,27 & 2 & 0,15 & 0,40 & 0,55 & - & - & - \\
\hline Lonchocarpus guillemineanus (Tul.) Malme & SI & 2 & 0,13 & 0,12 & 0,26 & 2 & 0,15 & 0,39 & 0,54 & - & - & - \\
\hline Pradosia lactescens (Vell.) Radlk. & ST & 3 & 0,20 & 0,06 & 0,12 & 3 & 0,22 & 0,32 & 0,54 & - & - & - \\
\hline Discophora guianensis Miers & SI & 2 & 0,13 & 0,12 & 0,25 & 2 & 0,15 & 0,39 & 0,53 & - & - & - \\
\hline Marlierea grandifolia $\mathrm{O}$. Berg & ST & 3 & 0,20 & 0,05 & 0,11 & 3 & 0,22 & 0,31 & 0,53 & - & - & - \\
\hline Eugenia beaurepairiana (Kiaersk.) D. Legrand & ST & 2 & 0,13 & 0,12 & 0,24 & 2 & 0,15 & 0,38 & 0,52 & - & - & - \\
\hline Myroxylon peruiferum L. f. & ST & 2 & 0,13 & 0,10 & 0,22 & 2 & 0,15 & 0,35 & 0,50 & - & - & - \\
\hline Simira glaziovii (K. Schum.) Steyerm. & ST & 3 & 0,20 & 0,04 & 0,08 & 3 & 0,22 & 0,28 & 0,50 & - & - & - \\
\hline Jacaratia heptaphylla (Vell.) A. DC. & SI & 2 & 0,13 & 0,10 & 0,21 & 2 & 0,15 & 0,35 & 0,49 & - & - & - \\
\hline Exellodendron gracile (Kuhlm.) Prance & ST & 2 & 0,13 & 0,09 & 0,20 & 2 & 0,15 & 0,33 & 0,48 & - & - & - \\
\hline Piptadenia paniculata Benth. & PI & 2 & 0,13 & 0,10 & 0,20 & 2 & 0,15 & 0,33 & 0,48 & - & - & - \\
\hline Coussarea contracta (Walp.) Müll. Arg. & SI & 3 & 0,20 & 0,03 & 0,06 & 3 & 0,22 & 0,26 & 0,48 & - & - & - \\
\hline Chrysophyllum januariense Eichler & ST & 3 & 0,20 & 0,02 & 0,05 & 3 & 0,22 & 0,25 & 0,47 & - & - & - \\
\hline Pouteria venosa subsp. amazonica T.D. Penn. & ST & 3 & 0,20 & 0,02 & 0,05 & 3 & 0,22 & 0,25 & 0,47 & - & - & - \\
\hline $\begin{array}{l}\text { Micropholis crassipedicellata (Mart. \& Eichler ex } \\
\text { Miq.) Pierre }\end{array}$ & ST & 2 & 0,13 & 0,09 & 0,18 & 2 & 0,15 & 0,32 & 0,46 & - & - & - \\
\hline Alseis floribunda Schott & ST & 2 & 0,13 & 0,09 & 0,18 & 2 & 0,15 & 0,31 & 0,46 & - & - & - \\
\hline Myrcia isaiana G.M. Barroso \& Peixoto & ST & 3 & 0,20 & 0,02 & 0,04 & 3 & 0,22 & 0,24 & 0,46 & - & - & - \\
\hline Naucleopsis oblongifolia (Kuhlm.) Carauta & ST & 3 & 0,20 & 0,02 & 0,04 & 3 & 0,22 & 0,23 & 0,46 & - & - & - \\
\hline Ocotea cernua (Nees) Mez & SI & 3 & 0,20 & 0,02 & 0,04 & 3 & 0,22 & 0,23 & 0,46 & - & - & - \\
\hline Tapirira guianensis Aubl. & PI & 3 & 0,20 & 0,02 & 0,04 & 3 & 0,22 & 0,23 & 0,46 & - & - & - \\
\hline Pourouma velutina Mart. ex Miq. & SI & 2 & 0,13 & 0,08 & 0,17 & 2 & 0,15 & 0,30 & 0,45 & - & - & - \\
\hline Inga cabelo T.D. Penn. & SI & 3 & 0,20 & 0,02 & 0,03 & 3 & 0,22 & 0,23 & 0,45 & - & - & - \\
\hline Swartzia apetala Raddi & ST & 3 & 0,20 & 0,01 & 0,03 & 3 & 0,22 & 0,23 & 0,45 & - & - & - \\
\hline Brosimum glaucum Taub. & SI & 3 & 0,20 & 0,01 & 0,03 & 3 & 0,22 & 0,22 & 0,45 & - & - & - \\
\hline Eugenia pyriflora $\mathrm{O}$. Berg & ST & 3 & 0,20 & 0,01 & 0,02 & 3 & 0,22 & 0,22 & 0,45 & - & - & - \\
\hline Rollinia laurifolia Schltdl. & SI & 1 & 0,07 & 0,14 & 0,30 & 1 & 0,07 & 0,37 & 0,44 & - & - & - \\
\hline
\end{tabular}

FLORESTA, Curitiba, PR, v. 41, n. 2, p. 321-334, abr./jun. 2011.

Paula, A. de; Soares, J. J. 


\begin{tabular}{|c|c|c|c|c|c|c|c|c|c|c|c|c|}
\hline Marlierea regeliana $\mathrm{O}$. Berg & ST & 3 & 0,20 & 0,01 & 0,02 & 3 & 0,22 & 0,22 & 0,44 & - & - & - \\
\hline Pouteria reticulata (Engl.) Eyma & ST & 3 & 0,20 & 0,01 & 0,02 & 3 & 0,22 & 0,22 & 0,44 & - & - & - \\
\hline Inga plana (Vell.) I. Alves & SI & 3 & 0,20 & 0,01 & 0,02 & 3 & 0,22 & 0,21 & 0,44 & - & - & - \\
\hline Psidium macrospermum $\mathrm{O}$. Berg & ST & 3 & 0,20 & 0,01 & 0,02 & 3 & 0,22 & 0,21 & 0,44 & - & - & - \\
\hline Mouriri arborea Gardner & ST & 3 & 0,20 & 0,01 & 0,01 & 3 & 0,22 & 0,21 & 0,43 & - & - & - \\
\hline Simaba subcymosa A. St.-Hil. \& Tul. & SI & 1 & 0,07 & 0,12 & 0,26 & 1 & 0,07 & 0,33 & 0,40 & - & - & - \\
\hline Peltogyne angustiflora Ducke & ST & 1 & 0,07 & 0,12 & 0,25 & 1 & 0,07 & 0,32 & 0,39 & - & - & - \\
\hline Zollernia modesta A.M. de Carvalho \& R.C. Barneby & ST & 1 & 0,07 & 0,12 & 0,25 & 1 & 0,07 & 0,32 & 0,39 & - & - & - \\
\hline Heisteria ovata Benth. & ST & 2 & 0,13 & 0,05 & 0,11 & 2 & 0,15 & 0,24 & 0,39 & - & - & - \\
\hline Cecropia hololeuca Miq. & PI & 1 & 0,07 & 0,11 & 0,24 & 1 & 0,07 & 0,31 & 0,38 & - & - & - \\
\hline Aspidosperma spruceanum Benth. ex Müll. Arg. & ST & 3 & 0,20 & 0,02 & 0,03 & 2 & 0,15 & 0,23 & 0,38 & - & - & - \\
\hline Virola bicuhyba (Schott) A.C. Sm. & ST & 2 & 0,13 & 0,05 & 0,10 & 2 & 0,15 & 0,23 & 0,38 & - & - & - \\
\hline Casearia javitensis Kunth & SI & 3 & 0,20 & 0,01 & 0,02 & 2 & 0,15 & 0,22 & 0,37 & - & - & - \\
\hline Myrciaria jaboticaba (Vell.) O. Berg & SI & 2 & 0,13 & 0,04 & 0,09 & 2 & 0,15 & 0,22 & 0,37 & - & - & - \\
\hline Ocotea conferta Coe Teixeira & ST & 2 & 0,13 & 0,04 & 0,09 & 2 & 0,15 & 0,22 & 0,37 & - & - & - \\
\hline Luehea mediterranea (Vell.) Angely & SI & 2 & 0,13 & 0,04 & 0,07 & 2 & 0,15 & 0,21 & 0,35 & - & - & - \\
\hline Coccoloba tenuifolia $\mathrm{L}$. & SI & 2 & 0,13 & 0,02 & 0,04 & 2 & 0,15 & 0,18 & 0,33 & - & - & - \\
\hline Deguelia longeracemosa (Benth.) Az.-Tozzi & SI & 2 & 0,13 & 0,02 & 0,05 & 2 & 0,15 & 0,18 & 0,33 & - & - & - \\
\hline Micropholis gardneriana (A. DC.) Pierre & ST & 2 & 0,13 & 0,02 & 0,05 & 2 & 0,15 & 0,18 & 0,33 & - & - & - \\
\hline Couepia carautae Prance & ST & 1 & 0,07 & 0,09 & 0,18 & 1 & 0,07 & 0,25 & 0,32 & - & - & - \\
\hline Couepia schottii Fritsch & ST & 2 & 0,13 & 0,02 & 0,04 & 2 & 0,15 & 0,17 & 0,32 & - & - & - \\
\hline Indet 1 & IN & 2 & 0,13 & 0,02 & 0,04 & 2 & 0,15 & 0,17 & 0,32 & - & - & - \\
\hline Lacistema recurvum Schnizlein in Mart. & ST & 2 & 0,13 & 0,02 & 0,04 & 2 & 0,15 & 0,17 & 0,32 & - & - & - \\
\hline Margaritaria nobilis $\mathrm{L} . \mathrm{f}$. & SI & 2 & 0,13 & 0,02 & 0,04 & 2 & 0,15 & 0,17 & 0,32 & - & - & - \\
\hline Marlierea estrellensis $\mathrm{O} . \mathrm{Berg}$ & ST & 2 & 0,13 & 0,02 & 0,04 & 2 & 0,15 & 0,17 & 0,32 & - & - & - \\
\hline Marlierea sp. & ST & 2 & 0,13 & 0,02 & 0,04 & 2 & 0,15 & 0,17 & 0,32 & - & - & - \\
\hline Tovomita brevistaminea Engl. & ST & 2 & 0,13 & 0,02 & 0,04 & 2 & 0,15 & 0,17 & 0,32 & - & - & - \\
\hline Swartzia myrtifolia var. elegans (Schott) R.S. Cowan & ST & 1 & 0,07 & 0,08 & 0,17 & 1 & 0,07 & 0,24 & 0,31 & - & - & - \\
\hline Eugenia moonioides O. Berg & ST & 1 & 0,07 & 0,08 & 0,17 & 1 & 0,07 & 0,23 & 0,31 & - & - & - \\
\hline Chrysophyllum sp. & ST & 2 & 0,13 & 0,02 & 0,03 & 2 & 0,15 & 0,16 & 0,31 & - & - & - \\
\hline Cordia sellowiana Cham. & SI & 2 & 0,13 & 0,01 & 0,03 & 2 & 0,15 & 0,16 & 0,31 & - & - & - \\
\hline Cryptocarya moschata Nees \& C. Mart. & SI & 2 & 0,13 & 0,01 & 0,03 & 2 & 0,15 & 0,16 & 0,31 & - & - & - \\
\hline Eugenia neoglomerata Sobral & ST & 2 & 0,13 & 0,01 & 0,03 & 2 & 0,15 & 0,16 & 0,31 & - & - & - \\
\hline Humiriastrum dentatum (Casar.) Cuatrec. & ST & 2 & 0,13 & 0,01 & 0,03 & 2 & 0,15 & 0,16 & 0,31 & - & - & - \\
\hline Naucleopsis mello-barretoi (Standl.) C.C. Berg & ST & 2 & 0,13 & 0,02 & 0,03 & 2 & 0,15 & 0,16 & 0,31 & - & - & - \\
\hline Pouteria psammophila (Mart.) Radlk. & ST & 2 & 0,13 & 0,01 & 0,02 & 2 & 0,15 & 0,16 & 0,31 & - & - & - \\
\hline Trichilia casaretti C. DC. & ST & 2 & 0,13 & 0,01 & 0,03 & 2 & 0,15 & 0,16 & 0,31 & - & - & - \\
\hline Spondias macrocarpa Engl. & SI & 1 & 0,07 & 0,08 & 0,16 & 1 & 0,07 & 0,22 & 0,30 & - & - & - \\
\hline Amphirrhox longifolia (A. St.-Hil.) Spreng. & ST & 2 & 0,13 & 0,01 & 0,01 & 2 & 0,15 & 0,15 & 0,30 & - & - & - \\
\hline Astronium concinnum Schott ex Spreng. & SI & 2 & 0,13 & 0,01 & 0,02 & 2 & 0,15 & 0,15 & 0,30 & - & - & - \\
\hline Casearia sp. 2 & ST & 2 & 0,13 & 0,01 & 0,02 & 2 & 0,15 & 0,15 & 0,30 & - & - & - \\
\hline Maytenus multiflora Reissek & ST & 2 & 0,13 & 0,01 & 0,02 & 2 & 0,15 & 0,15 & 0,30 & - & - & - \\
\hline Ocotea teleiandra (Meisn.) Mez & $\mathrm{ST}$ & 2 & 0,13 & 0,01 & 0,02 & 2 & 0,15 & 0,15 & 0,30 & - & - & - \\
\hline Plinia involucrata (O. Berg) McVaugh & ST & 2 & 0,13 & 0,01 & 0,02 & 2 & 0,15 & 0,15 & 0,30 & - & - & - \\
\hline Simira grazielae Peixoto & ST & 2 & 0,13 & 0,01 & 0,02 & 2 & 0,15 & 0,15 & 0,30 & - & - & - \\
\hline Trichilia sp.2 & SI & 2 & 0,13 & 0,01 & 0,02 & 2 & 0,15 & 0,15 & 0,30 & - & - & - \\
\hline Salicaceae & IN & 1 & 0,07 & 0,07 & 0,15 & 1 & 0,07 & 0,21 & 0,29 & - & - & - \\
\hline Talisia coriacea Radlk. & ST & 2 & 0,13 & 0,01 & 0,01 & 2 & 0,15 & 0,15 & 0,29 & - & - & - \\
\hline $\begin{array}{l}\text { Amaioua intermedia var. brasiliensis (Rich. ex } \\
\text { DC.) Steyerm. }\end{array}$ & SI & 2 & 0,13 & 0,00 & 0,01 & 2 & 0,15 & 0,14 & 0,29 & - & - & - \\
\hline Annona cacans Warm. & SI & 2 & 0,13 & 0,01 & 0,01 & 2 & 0,15 & 0,14 & 0,29 & - & - & - \\
\hline Eugenia brasiliensis Lam. & ST & 2 & 0,13 & 0,01 & 0,01 & 2 & 0,15 & 0,14 & 0,29 & - & - & - \\
\hline Exostyles venusta Schott ex Spreng. & SI & 2 & 0,13 & 0,01 & 0,01 & 2 & 0,15 & 0,14 & 0,29 & - & - & - \\
\hline Melanopsidium nigrum Colla & SI & 2 & 0,13 & 0,00 & 0,01 & 2 & 0,15 & 0,14 & 0,29 & - & - & - \\
\hline Posoqueria latifolia (Rudge) Roem. \& Schult. & SI & 2 & 0,13 & 0,01 & 0,01 & 2 & 0,15 & 0,14 & 0,29 & - & - & - \\
\hline
\end{tabular}




\begin{tabular}{|c|c|c|c|c|c|c|c|c|c|c|c|c|}
\hline Diplotropis incexis Rizzini \& A. Mattos & SI & 1 & 0,07 & 0,06 & 0,13 & 1 & 0,07 & 0,20 & 0,27 & - & - & - \\
\hline $\begin{array}{l}\text { Hymenaea courbaril var. stilbocarpa (Hayne) Y.T. } \\
\text { Lee \& Langenh. }\end{array}$ & ST & 1 & 0,07 & 0,06 & 0,12 & 1 & 0,07 & 0,18 & 0,26 & - & - & - \\
\hline Qualea megalocarpa Stafleu & ST & 1 & 0,07 & 0,05 & 0,10 & 1 & 0,07 & 0,16 & 0,24 & - & - & - \\
\hline Schoepfia brasiliensis A. DC. & ST & 1 & 0,07 & 0,04 & 0,08 & 1 & 0,07 & 0,15 & 0,22 & - & - & - \\
\hline Cecropia glaziovi Snethlage & PI & 1 & 0,07 & 0,03 & 0,07 & 1 & 0,07 & 0,14 & 0,21 & - & - & - \\
\hline Ixora warmingii Müll. Arg. & PI & 1 & 0,07 & 0,03 & 0,07 & 1 & 0,07 & 0,14 & 0,21 & - & - & - \\
\hline Jacaratia spinosa (Aubl.) A. DC. & SI & 1 & 0,07 & 0,03 & 0,07 & 1 & 0,07 & 0,14 & 0,21 & - & - & - \\
\hline Indet 2 & IN & 1 & 0,07 & 0,03 & 0,07 & 1 & 0,07 & 0,13 & 0,21 & - & - & - \\
\hline Lauraceae & SI & 1 & 0,07 & 0,03 & 0,06 & 1 & 0,07 & 0,13 & 0,20 & - & - & - \\
\hline Pouteria cuspidata (A. DC.) Baehni & ST & 1 & 0,07 & 0,02 & 0,04 & 1 & 0,07 & 0,11 & 0,18 & - & - & - \\
\hline Himatanthus phagedaenicus (Mart.) Woodson & SI & 1 & 0,07 & 0,02 & 0,04 & 1 & 0,07 & 0,10 & 0,18 & - & - & - \\
\hline Xylopia ochrantha Mart. & ST & 1 & 0,07 & 0,02 & 0,04 & 1 & 0,07 & 0,10 & 0,18 & - & - & - \\
\hline Ephedranthus sp. & IN & 1 & 0,07 & 0,02 & 0,03 & 1 & 0,07 & 0,10 & 0,17 & - & - & - \\
\hline Eugenia itapemirimensis Cambess. & ST & 1 & 0,07 & 0,02 & 0,03 & 1 & 0,07 & 0,10 & 0,17 & - & - & - \\
\hline Hirtella sp. & ST & 1 & 0,07 & 0,01 & 0,03 & 1 & 0,07 & 0,09 & 0,17 & - & - & - \\
\hline Spondias venulosa (Engl.) Engl. & SI & 1 & 0,07 & 0,01 & 0,02 & 1 & 0,07 & 0,09 & 0,17 & - & - & - \\
\hline Chrysobalanaceae & ST & 1 & 0,07 & 0,01 & 0,02 & 1 & 0,07 & 0,09 & 0,16 & - & - & - \\
\hline Coccoloba longipes S. Moore & SI & 1 & 0,07 & 0,01 & 0,02 & 1 & 0,07 & 0,09 & 0,16 & - & - & - \\
\hline Myrtaceae 3 & ST & 1 & 0,07 & 0,01 & 0,02 & 1 & 0,07 & 0,09 & 0,16 & - & - & - \\
\hline Trichilia sp.1 & SI & 1 & 0,07 & 0,01 & 0,02 & 1 & 0,07 & 0,09 & 0,16 & - & - & - \\
\hline Allophylus petiolulatus Radlk. & ST & 1 & 0,07 & 0,01 & 0,02 & 1 & 0,07 & 0,08 & 0,16 & - & - & - \\
\hline Eugenia sp.3 & ST & 1 & 0,07 & 0,01 & 0,02 & 1 & 0,07 & 0,08 & 0,16 & - & - & - \\
\hline Ocotea argentea $\mathrm{Mez}$ & ST & 1 & 0,07 & 0,01 & 0,02 & 1 & 0,07 & 0,08 & 0,16 & - & - & - \\
\hline $\begin{array}{l}\text { Pseudopiptadenia contorta (DC.) G.P. Lewis \& } \\
\text { M.P. Lima }\end{array}$ & SI & 1 & 0,07 & 0,01 & 0,02 & 1 & 0,07 & 0,08 & 0,16 & - & - & - \\
\hline Rubiaceae & IN & 1 & 0,07 & 0,01 & 0,02 & 1 & 0,07 & 0,08 & 0,16 & - & - & - \\
\hline Actinostemon estrellensis var. latifolius Pax & ST & 1 & 0,07 & 0,01 & 0,01 & 1 & 0,07 & 0,08 & 0,15 & - & - & - \\
\hline Annonaceae & SI & 1 & 0,07 & 0,01 & 0,01 & 1 & 0,07 & 0,08 & 0,15 & - & - & - \\
\hline Byrsonima cacaophila W.R. Anderson & PI & 1 & 0,07 & 0,00 & 0,01 & 1 & 0,07 & 0,08 & 0,15 & - & - & - \\
\hline Casearia decandra Jacq. & SI & 1 & 0,07 & 0,01 & 0,01 & 1 & 0,07 & 0,08 & 0,15 & - & - & - \\
\hline Eugenia sp.1 & ST & 1 & 0,07 & 0,01 & 0,01 & 1 & 0,07 & 0,08 & 0,15 & - & - & - \\
\hline Helicostylis tomentosa (Poepp. \& Endl.) Rusby & ST & 1 & 0,07 & 0,00 & 0,01 & 1 & 0,07 & 0,08 & 0,15 & - & - & - \\
\hline Indet 3 & IN & 1 & 0,07 & 0,00 & 0,01 & 1 & 0,07 & 0,08 & 0,15 & - & - & - \\
\hline Manilkara salzmannii (A. DC.) H.J. Lam & ST & 1 & 0,07 & 0,01 & 0,01 & 1 & 0,07 & 0,08 & 0,15 & - & - & - \\
\hline Myrtaceae 4 & ST & 1 & 0,07 & 0,01 & 0,01 & 1 & 0,07 & 0,08 & 0,15 & - & - & - \\
\hline Sterculia elata Ducke & ST & 1 & 0,07 & 0,01 & 0,01 & 1 & 0,07 & 0,08 & 0,15 & - & - & - \\
\hline Trichilia surumuensis C. DC. & ST & 1 & 0,07 & 0,01 & 0,01 & 1 & 0,07 & 0,08 & 0,15 & - & - & - \\
\hline Casearia sp.1 & ST & 1 & 0,07 & 0,00 & 0,01 & 1 & 0,07 & 0,07 & 0,15 & - & - & - \\
\hline Connarus detersus Planch. & ST & 1 & 0,07 & 0,00 & 0,01 & 1 & 0,07 & 0,07 & 0,15 & - & - & - \\
\hline Cryptocarya saligna $\mathrm{Mez}$ & SI & 1 & 0,07 & 0,00 & 0,01 & 1 & 0,07 & 0,07 & 0,15 & - & - & - \\
\hline Esenbeckia grandiflora Mart. & ST & 1 & 0,07 & 0,00 & 0,01 & 1 & 0,07 & 0,07 & 0,15 & - & - & - \\
\hline Eugenia candolleana DC. & ST & 1 & 0,07 & 0,00 & 0,01 & 1 & 0,07 & 0,07 & 0,15 & - & - & - \\
\hline Eugenia sp.2 & ST & 1 & 0,07 & 0,00 & 0,01 & 1 & 0,07 & 0,07 & 0,15 & - & - & - \\
\hline Fabaceae 1 & SI & 1 & 0,07 & 0,00 & 0,01 & 1 & 0,07 & 0,07 & 0,15 & - & - & - \\
\hline Fabaceae 2 & SI & 1 & 0,07 & 0,00 & 0,01 & 1 & 0,07 & 0,07 & 0,15 & - & - & - \\
\hline Guarea juglandiformis T.D. Penn. & ST & 1 & 0,07 & 0,00 & 0,01 & 1 & 0,07 & 0,07 & 0,15 & - & - & - \\
\hline Guatteria sp. & SI & 1 & 0,07 & 0,00 & 0,01 & 1 & 0,07 & 0,07 & 0,15 & - & - & - \\
\hline Hirtella sprucei Benth. ex Hook. f. & ST & 1 & 0,07 & 0,00 & 0,01 & 1 & 0,07 & 0,07 & 0,15 & - & - & - \\
\hline Licania belemii Prance & SI & 1 & 0,07 & 0,00 & 0,01 & 1 & 0,07 & 0,07 & 0,15 & - & - & - \\
\hline Myrcia sp.2 & ST & 1 & 0,07 & 0,00 & 0,01 & 1 & 0,07 & 0,07 & 0,15 & - & - & - \\
\hline Myrocarpus frondosus Allemão & ST & 1 & 0,07 & 0,00 & 0,01 & 1 & 0,07 & 0,07 & 0,15 & - & - & - \\
\hline Myrtaceae 1 & ST & 1 & 0,07 & 0,00 & 0,01 & 1 & 0,07 & 0,07 & 0,15 & - & - & - \\
\hline Myrtaceae 2 & ST & 1 & 0,07 & 0,00 & 0,01 & 1 & 0,07 & 0,07 & 0,15 & - & - & - \\
\hline Ouratea cuspidata Tiegh. & SI & 1 & 0,07 & 0,00 & 0,01 & 1 & 0,07 & 0,07 & 0,15 & - & - & - \\
\hline Protium aracouchini (Aubl.) Marchand & SI & 1 & 0,07 & 0,00 & 0,01 & 1 & 0,07 & 0,07 & 0,15 & - & - & - \\
\hline
\end{tabular}

FLORESTA, Curitiba, PR, v. 41, n. 2, p. 321-334, abr./jun. 2011.

Paula, A. de; Soares, J. J. 


\begin{tabular}{|c|c|c|c|c|c|c|c|c|c|c|c|c|}
\hline Psychotria sp. & PI & 1 & 0,07 & 0,00 & 0,01 & 1 & 0,07 & 0,07 & 0,15 & - & - & - \\
\hline Rauia sp. & IN & 1 & 0,07 & 0,00 & 0,01 & 1 & 0,07 & 0,07 & 0,15 & - & - & - \\
\hline Swartzia flaemingii Raddi & ST & 1 & 0,07 & 0,00 & 0,01 & 1 & 0,07 & 0,07 & 0,15 & - & - & - \\
\hline Cordia trichoclada DC. & SI & 1 & 0,07 & 0,00 & 0,00 & 1 & 0,07 & 0,07 & 0,14 & - & - & - \\
\hline Guatteria peckoltiana R.E. Fr. & SI & 1 & 0,07 & 0,00 & 0,00 & 1 & 0,07 & 0,07 & 0,14 & - & - & - \\
\hline Machaerium fulvovenosum Lima & ST & 1 & 0,07 & 0,00 & 0,00 & 1 & 0,07 & 0,07 & 0,14 & - & - & - \\
\hline $\begin{array}{l}\text { Myrcia multiflora var. glaucescens (O. Berg) D. } \\
\text { Legrand }\end{array}$ & ST & 1 & 0,07 & 0,00 & 0,00 & 1 & 0,07 & 0,07 & 0,14 & - & - & 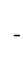 \\
\hline Myrcia sp.1 & ST & 1 & 0,07 & 0,00 & 0,00 & 1 & 0,07 & 0,07 & 0,14 & - & - & - \\
\hline Myrcia sp.3 & ST & 1 & 0,07 & 0,00 & 0,00 & 1 & 0,07 & 0,07 & 0,14 & - & - & - \\
\hline Ocotea odorifera (Vellozo) Rohwer & ST & 1 & 0,07 & 0,00 & 0,00 & 1 & 0,07 & 0,07 & 0,14 & - & - & - \\
\hline Total & & 1519 & 100,3 & 268,7 & 100,0 & 1343 & 99,64 & 199,95 & 300,0 & & & \\
\hline
\end{tabular}

Em relação à FA, R. bahiensis foi encontrada em $72 \%$ das parcelas amostradas. Outras espécies com número de indivíduos relativamente alto, como E. macrophylla, D. guianense, $H$. trinervis, E. ubensis e E. ramiflora, foram observadas apresentando praticamente um indivíduo por parcela (Tabela 1).

No estudo em questão, foram necessárias 34 espécies (13\% da riqueza) para atingir $50 \%$ do número de indivíduos amostrados (Tabela 1). Em trabalhos como os de Paula et al. (2009) e Silva; Nascimento (2001), ambos com índices de H' abaixo de 4,00 nats, o número de espécies necessárias para atingir $50 \%$ dos indivíduos foi bem menor, sendo de sete e cinco, respectivamente, ou seja, cerca de $6 \%$ das espécies encontradas em cada trabalho.

Em relação aos valores de DR e FR, vale ressaltar que apenas duas espécies, $R$. bahiensis e $S$. speciosa, obtiveram destaque, mesmo que não tão pronunciado (Tabela 1). No entanto, maior relevância deve ser dada para as espécies com densidade muito baixa, 78 (29\%) com apenas um indivíduo. Martins (1993) observou que esse percentual é superior a 20\%, tanto para as florestas amazônicas quanto para as atlânticas, o que corrobora o valor encontrado no presente estudo.

É de se esperar que, quanto mais avançado o estádio de desenvolvimento da floresta, maior será a porcentagem de espécies raras, já que a riqueza em espécies tende a aumentar, em detrimento das poucas populações com grande número de indivíduos, características das fases iniciais. No entanto, vale ressaltar que em fragmentos com alto grau de perturbação o número de espécies raras também pode ser alto, como verificado em Meira Neto et al. (1997).

Os maiores VC observados foram das espécies $R$. bahiensis, E. macrophylla, F. gomelleira, S. speciosa, $H$. trinervis, D. guianense e $C$. curranii (Tabela 1), sendo que as espécies com os maiores desequilíbrios nos valores de DR e DoR foram E. macrophylla, F. gomelleira, H. trinervis e C. curranii, apresentando densidades muito baixas e grande porte de indivíduos. Ao somarem-se os dados de FR para obtenção do VI, observa-se que espécies de pequeno porte passam a figurar entre as mais importantes. Esse é o caso de E. ubensis, E. ramiflora, S. oblongifolia, P. hispida, P. rohrii, E. excelsa, T. kuhlmannii e C. lucida var. polyantha.

Martins (1993) ressaltou que o elevado número de espécies raras promove uma equiparação dos valores de importância em níveis muito baixos. $\mathrm{O}$ autor afirmou ainda que não só a proporção de espécies raras responde pela semelhança dos valores mais baixos de importância, como também a diversidade de espécies pode implicar a insignificância relativa de grande parte delas, ou seja, cada espécie contribui com um valor de importância muito baixo.

Na tabela 1 encontram-se os índices de agregação das espécies que foram amostradas com mais de 10 indivíduos (39 espécies). Foram encontradas 10 espécies com padrão de distribuição espacial agregado e 29 com padrão aleatório. Nenhuma das espécies apresentou o padrão regular. Em relação aos grupos ecológicos, das seis secundárias iniciais observadas, cinco possuem o padrão aleatório, e das 33 secundárias tardias, nove $(27,27 \%)$ possuem o padrão agregado e 24 o aleatório $(72,73 \%)$.

No presente trabalho, as espécies com número de indivíduos maior ou igual a 20 (R. bahiensis, E. ubensis, E. ramiflora, D. guianense, S. oblongifolia, C. brasiliensis, P. híspida e S. blanchetianum) apresentaram padrão espacial "aleatório". No trabalho de Jesus; Rolim (2005), todas apresentaram padrão "agrupado". Segundo os autores, a ocorrência de agrupamento pode ser considerada uma característica das espécies mais abundantes da floresta tropical.

$\mathrm{Na}$ avaliação dos grupos ecológicos, é possível observar o grande destaque obtido pelas secundárias tardias na maioria dos parâmetros fitossociológicos. Em relação ao número de indivíduos e à DR, as secundárias tardias acumularam 79,70\%, seguidas das secundárias iniciais, com $18,30 \%$, e das 
pioneiras, com apenas 1,07\% (Tabela 2). Valores semelhantes foram observados para FA e FR (Tabela 2), com as secundárias iniciais somando $63,78 \%$ da AB, tendo as secundárias tardias 35,86\% (Tabela 2). Ao serem observados os valores de DoR, é possível verificar um equilíbrio entre as secundárias tardias e as iniciais (Tabela 2). Os índices de VC e VI apresentaram o mesmo padrão, com as secundárias tardias tendo mais do que o dobro dos valores das secundárias iniciais (Tabela 2). A predominância de espécies mais tolerantes ao sombreamento também foi observado por Jesus; Rolim (2005). Esses dados reforçam a conclusão de que o estádio sucessional do estande estudado encontra-se avançado.

Tabela 2. Parâmetros fitossociológicos dos grupos ecológicos de um estande florestal na Reserva Biológica de Sooretama, sendo: GE - grupo ecológico, PI - pioneira, SI - secundária inicial, ST - secundária tardia, IN - indeterminada, NI - número de indivíduos, DR - densidade relativa, $\mathrm{AB}$ - área basal, DoR - dominância relativa, FA - frequência absoluta, FR - frequência relativa, VC - valor de cobertura e VI - valor de importância.

Table 2. Phytosociological parameters of ecological groups of a forest stand in Sooretama Biological Reserve, where: GE - ecological group, PI - pioneer, SI - secondary initial ST - late secondary, IN - indefinite, NI - number of individuals, DR - relative density, AB - basal area, DoR relative dominance, FA - absolute frequency, FR - relative frequency, VC - value covering and VI - importance value.

\begin{tabular}{lcccccccc}
\hline GE & NI & DR & AB & DoR & FA & FR & VC & VI \\
\hline PI & 16 & 1,07 & 0,34 & 0,73 & 15,00 & 1,19 & 1,79 & 2,90 \\
SI & 277 & 18,30 & 171,37 & 47,44 & 268,00 & 19,90 & 65,67 & 85,67 \\
ST & 1210 & 79,70 & 96,35 & 50,53 & 1044,00 & 77,65 & 130,10 & 207,90 \\
IN & 16 & 1,08 & 0,62 & 1,33 & 16,00 & 1,26 & 2,36 & 3,57 \\
\hline Total & 1519 & 100,00 & 268,69 & 100,00 & 1343,00 & 100,00 & 200,00 & 300,00 \\
\hline
\end{tabular}

As distribuições diamétricas da comunidade como um todo e dos grupos ecológicos das pioneiras, secundárias iniciais e secundárias tardias apresentam formato de "J" reverso (Figuras 1 e 2). Segundo Meyer (1952), esse formato é comum em florestas inequiâneas, estando o maior número de indivíduos dispostos nas menores classes de diâmetro, reduzindo gradativamente em direção às maiores. As distribuições diamétricas observadas nas figuras 1 e 2 apresentaram-se desbalanceadas, ou seja, a razão entre o número de indivíduos de classes subsequentes não é constante (LIOCOURT, 1898, citado por MEYER, 1952).

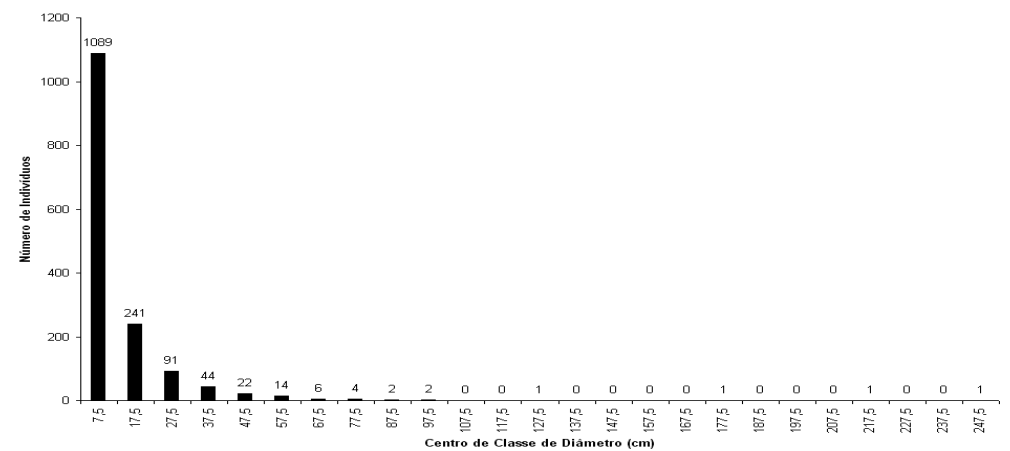

Figura 1. Distribuição diamétrica dos indivíduos amostrados no levantamento fitossociológico realizado na ReBio de Sooretama.

Figure 1. Diameter distribution of the individuals in the phytosociological survey carried out in ReBio of Sooretama.

$\mathrm{Na}$ figura 2, as espécies pioneiras apresentam uma distribuição diamétrica restrita às menores classes diamétricas, demonstrando uma pequena contribuição na estrutura horizontal do estande. Por outro lado, a distribuição das secundárias iniciais foi ampla, sendo que a partir da classe $97,5 \mathrm{~cm}$ apresentou-se descontínua (Figura 2). Os indivíduos que se apresentaram nas maiores classes diamétricas foram: P. rohrii $(127,5 \mathrm{~cm})$, C. curranii $(177,5 \mathrm{~cm}), F$. gomelleira $(217,5 \mathrm{~cm})$ e E. macrophylla $(247,5$ $\mathrm{cm})$.

FLORESTA, Curitiba, PR, v. 41, n. 2, p. 321-334, abr./jun. 2011.

Paula, A. de; Soares, J. J. 


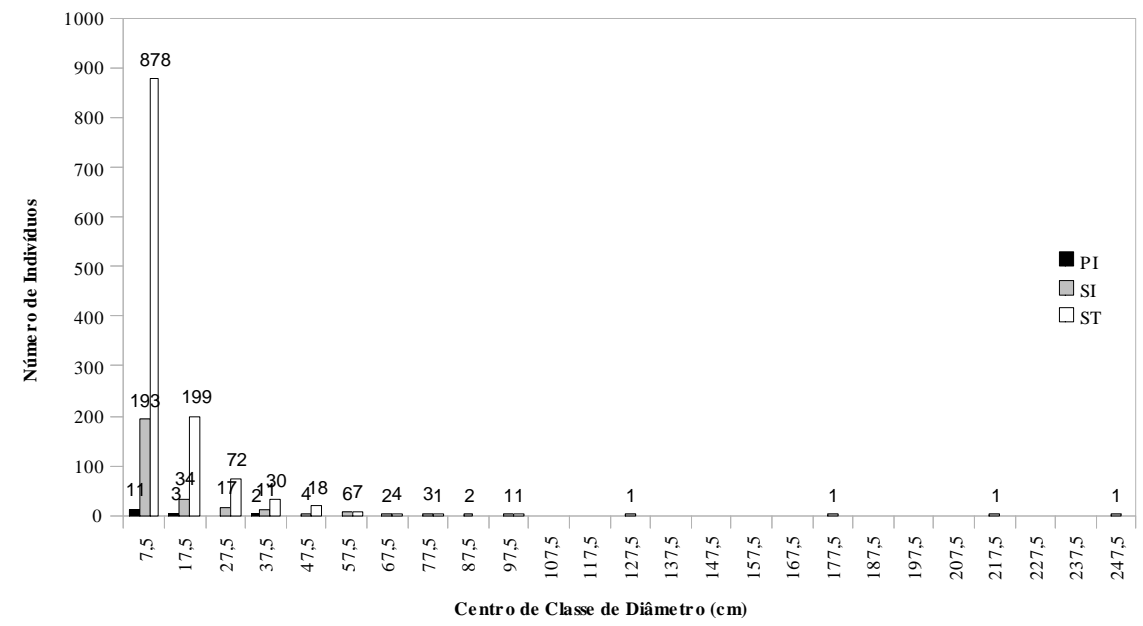

Figura 2. Distribuição diamétrica dos indivíduos amostrados no levantamento fitossociológico realizado na ReBio de Sooretama, classificados nos grupos ecológicos das pioneiras, secundárias iniciais e secundárias tardias.

Figure 2. Diameter distribution of the individuals in the phytosociological survey carried out in ReBio of Sooretama, falling within ecological groups of pioneers, early secondary and late secondary.

Na tabela 3 pode-se observar que as espécies raras foram encontradas, em sua maioria, nas menores classes de diâmetro. Esse fato demonstra que essas espécies estão entrando no perfil, ou seja, são espécies que passaram a encontrar condições favoráveis ao seu estabelecimento e estão iniciando seu processo de colonização no estande estudado. Na classe de diâmetro de $7,5 \mathrm{~cm}$, predominaram as espécies secundárias tardias, seguidas das secundárias iniciais, mantendo, dessa forma, o padrão apresentado nos outros parâmetros fitossociológicos (Tabela 3).

Tabela 3. Distribuição diamétrica das espécies raras por grupo ecológico de um estande florestal na Reserva Biológica de Sooretama, sendo: GE - grupo ecológico, PI - pioneira, SI - secundária inicial, ST - secundária tardia e IN - indeterminada.

Table 3. Diameter distribution of rare species by ecological group of a forest stand in Sooretama Biological Reserve, where: GE - ecological group, PI - pioneer, SI - secondary initial, ST - late secondary and IN - indefinite.

\begin{tabular}{lcccccccc}
\hline GE & $\mathbf{7 , 5}$ & $\mathbf{1 7 , 5}$ & $\mathbf{2 7 , 5}$ & $\mathbf{3 7 , 5}$ & $\mathbf{5 7 , 5}$ & $\mathbf{9 7 , 5}$ & $\mathbf{1 7 7 , 5}$ & Total \\
\hline PI & 2 & 2 & 0 & 1 & 0 & 0 & 0 & 5 \\
SI & 15 & 3 & 2 & 2 & 0 & 1 & 1 & 24 \\
ST & 29 & 5 & 4 & 3 & 1 & 0 & 0 & 42 \\
IN & 3 & 2 & 1 & 0 & 1 & 0 & 0 & 7 \\
\hline Total & 49 & 12 & 7 & 6 & 2 & 1 & 1 & 78 \\
\hline
\end{tabular}

\section{CONCLUSÕES}

- É possível concluir que o estádio sucessional do estande é avançado. Isso pode ser verificado quando se constata o predomínio do grupo de espécies tardias, tanto em relação à florística (63\% pertencem ao grupo das secundárias tardias, $30 \%$ de secundárias iniciais e apenas 3\% de pioneiras) quanto em relação aos parâmetros fitossociológicos. Esses dados demonstram que as características ambientais no estande encontram-se favoráveis ao desenvolvimento das espécies tolerantes ao sombreamento.

- Outras informações que corroboram essa conclusão são: o alto índice de diversidade encontrado (4,87 nats) e o grande equilíbrio na distribuição dos indivíduos por espécie (foram necessárias 34 espécies, ou seja, $13 \%$ da riqueza, para atingir $50 \%$ do número de indivíduos amostrados). 
- Esse equilíbrio na distribuição dos indivíduos também pode ser constatado pela ausência de um grande predomínio de qualquer espécie em relação à densidade. Além disso, a presença de um elevado número de espécies raras do grupo das secundárias tardias (42) pode ser atribuída às condições de sombreamento.

- A distribuição diamétrica também demonstra o estádio sucessional avançado. Ao se analisarem os grupos ecológicos, percebe-se que a distribuição apresentada pelas pioneiras foi truncada, sendo que a das secundárias iniciais foi ampla, o que evidencia a predominância de espécies tolerantes ao sombreamento nos estágios iniciais de crescimento.

\section{REFERÊNCIAS}

AGUIRRE, A. Estudo sobre o parque de reserva, refúgio e criação de animais silvestres Sooretama, no município de Linhares, Estado do Espírito Santo. Boletim do Ministério da Agricultura, v. 36, n. 4 - 6, p. 1 - 52. 1951.

ANACLETO, T. C. Plano de pesquisa para a Reserva Biológica de Sooretama - documento básico. IBAMA, 1997. 48 p.

APG II. An update of the Angiosperm Phylogeny Group classification for the orders and families of flowering plants: APG II. Botanical Journal of the Linnean Society v. 141, p. 399 - 436, 2003.

BORGO, I. A. L.; ROSA, L. B. R. de A.; PACHECO, R. J. C. Norte do Espírito Santo: ciclo madeireiro e povoamento (1810-1960). EDUFES: Vitória, 1996. 178 p.

DAVIS, S. D.; HEYWOOD, V. H.; HERRERA-MACBRYDE, O.; VILLA-LOBOS, J.; HAMILTON, A. C. Tabuleiro forest of northern Espírito Santo - south-eastern Brazil. In: Centers of Plant Diversity - a guide and strategy for their conservation, v. 3, p. 369 - 372, 1997.

EGLER, W. Rio Doce, enigma do passado, promessa no presente. Bol. Geogr. v. 1, n. 7, p. 42 - 46. 1954.

FERREIRA, L. M.; BORGES, G. C.; ROCHA, S. B. Plano de manejo - Reserva Biológica de Sooretama. IBDF/FBCN, 1981. 115 p.

GANDOLFI, S.; LEITÃO FILHO, H. F.; BEZERRA, C. L. F. Levantamento florístico e caráter sucessional das espécies arbustivo-arbóreas de uma floresta mesófila semidecídua no município de Guarulhos, SP. Revista Brasileira de Biologia, v. 55, n. 4, p. 753 - 767. 1995.

HEINSDIJK, D.; MACEDO, J. G. D. E.; ANDEL, S.; ASCOLY, R. B. A floresta do Norte do Espírito Santo. Rio de Janeiro, Ministério da Agricultura, Departamento de Recursos Naturais Renováveis, n. 7, $1965.69 \mathrm{p}$.

INSTITUTO BRASILEIRO DE GEOGRAFIA E ESTATÍSTICA (IBGE). Geografia do Brasil - Região Sudeste. Rio de Janeiro, SERGRAF, v. 3, 667 p., 1977.

Mapa de vegetação do Brasil 1:5.000.000. Diretoria de Geociências, Rio de Janeiro. 2004.

INSTITUTO DE PESQUISAS DA MATA ATLÂNTICA (IPEMA). Conservação da Mata Atlântica no Estado do Espírito Santo: cobertura florestal e unidades de conservação. Vitória, ES: IPEMA, 2005. $142 \mathrm{p}$.

JESUS, R. M.; ROLIM, S. G. Fitossociologia da Mata Atlântica de Tabuleiro. Viçosa: Sociedade de Investigações Florestais, Documento SIF v. 19, p. 149, 2005.

KREBS, C. J. Ecological methodology. Harper \& Row, New York, USA. 1989. 654 p.

LÓPEZ, J. A. Caracterização fitossociológica e avaliação econômica de um fragmento de Mata Atlântica secundária, município de Linhares-ES. 71 f. Dissertação (Mestrado), Universidade Federal de Viçosa, Viçosa, 1996.

MARTINS, F. R. Estrutura de uma floresta mesófila. 2. ed., Campinas (SP): Editora da UNICAMP, 1993. $246 \mathrm{p}$. 
MEIRA NETO, J. A. A.; SOUZA, A. L.; SILVA, A. F.; PAULA, A. Estrutura de uma Floresta Estacional Semidecidual Submontana em área diretamente afetada pela Usina Hidrelétrica de Pilar, Ponte Nova, Zona da Mata de Minas Gerais. Revista Árvore v. 21, n. 3, p. 337 - 344, 1997.

MEYER, H. A. Structure, growth, and drain in balanced uneven-aged forests. Journal of Forestry, v. 50, p. $85-92,1952$.

MUELLER-DOMBOIS, D.; ELLENBERG, H. Aims and methods of vegetation ecology. New York: Willey \& Sons, 1974. 547 p.

PAULA, A.; LOPES, W. P.; SILVA. A. F. Florística e estrutura de fragmentos florestais no entorno da lagoa Juparanã, Linhares, Espírito Santo, Brasil. Bol. Mus. Biol. Mello Leitão (N. Sér.) v. 26, p. 5 - 23. 2009.

PEIXOTO, A. L.; GENTRY, A. Diversidade e composição florística de mata de tabuleiro na Reserva de Linhares (Espírito Santo, Brasil). Revista Brasileira de Botânica v. 13, p. 19 - 25. 1990.

PEIXOTO, A. L.; SILVA, I. M. Tabuleiro forest of northern Espírito Santo - south-eastern Brazil. In: DAVIS, S. D.; HEYWOOD, V. H.; HERRERA-KMACBRYDE; O. VILLA-LOBOS, J.; HAMILTONS, A. C. (Eds.). Centres of plant diversity - a guide and strategy for their conservation. WWF e IUCN, v. 3. 1997. p. $369-372$.

PIELOU, E. C. Ecological diversity. New York, Willey, 1975. 165 p.

RIZZINI, C. M.; ADUAN, R. E.; JESUS, R. M.; GARAY, I. Floresta Pluvial de Tabuleiro, Linhares, ES, Brasil, sistemas primários e secundários. Leandra, v. 12, p. 54 - 76. 1997.

RIZZINI, C. T. Tratado de fitogeografia do Brasil - aspectos ecológicos, sociológicos e florísticos. Rio de Janeiro, Âmbito Cultural Edições Ltda., 2. ed., 1997, 747 p.

ROSOT, N. C.; AMARAL-MACHADO, S.; FIGUEIREDO FILHO, A. Análise estrutural de uma floresta tropical como subsídio básico para elaboração de um plano de manejo florestal. In: CONGRESSO NACIONAL SOBRE ESSÊNCIAS NATIVAS. 1982. Campos do Jordão, SP, parte I: Anais, Campos do Jordão, 1982. p. 468 - 490.

RUSCHI, A. Fitogeografia do Estado do Espírito Santo. Bol. Mus. Biol. Mello Leitão, Série Botânica, v. 1, p. 353. 1950.

SALOMÃO, A. L. F. Subsídios técnicos para a elaboração do plano de manejo da Floresta Nacional do Rio Preto - ES. 151 p. Tese (Doutorado). Universidade Federal de Viçosa, Viçosa, 1998.

SHEPHERD, G. J. Fitopac 1 - manual do usuário. Campinas, SP: Universidade Estadual de Campinas. 1995. $88 \mathrm{p}$.

SILVA, A. F. Composição florística e estrutura fitossociológica do estrato arbóreo da Reserva Florestal Professor Augusto Ruschi, São José dos Campos, SP. 163 p. Tese (Doutorado) Universidade Estadual de Campinas, Campinas, SP. 1989.

SILVA, A. F.; LEITÃO FILHO, H. F. Composição florística e estrutura de um trecho de Mata Atlântica de encosta no município de Ubatuba (São Paulo, Brasil). Revista Brasileira de Botânica v. 5, p. 43 - 52. 1982.

SILVA, G. C.; NASCIMENTO, M. T. Fitossociologia de uma mata de tabuleiro. Revista Brasileira de Botânica, v. 24, n. 1, p. 51 - 62. 2001.

SOUZA, A. L.; MEIRA NETO, J. A. A.; SCHETTINO, S. Avaliação florística, fitossociológica e paramétrica de um fragmento de floresta atlântica secundária, município de Pedro Canário, Espírito Santo. Viçosa: Sociedade de Investigações Florestais, Documento SIF, v. 18, p.121. 1998a.

SOUZA, A. L.; MEIRA NETO, J. A. A.; SCHETTINO, S. Avaliação florística, fitossociológica e paramétrica de um fragmento de floresta atlântica secundária, município de Caravelas, Bahia. Viçosa: Sociedade de Investigações Florestais, Documento SIF, v. 19, p. 117. 1998b.

THOMAZ, L. D.; MONTEIRO, R. Composição florística da Mata Atlântica de encosta da Estação Biológica de Santa Lúcia, município de Santa Teresa - ES. Boletim do Museu de Biologia Mello Leitão, Nova Série, v. 7, p. 48. 1997. 